\title{
Ensino de Ciências nos Anos Iniciais e a Formação Continuada de Professores em Ambientes Virtuais Colaborativos
}

(Science Teaching in the Early Years and the Teachers Continuing Education in Collaborative Virtual Environments)

\section{JOSÉ FRANCISCO FLORES, JOÃO BERNARDES DA ROCHA FILHO e LUCIUS RAFAEL SICHONANY SAMUEL}

Pontifícia Universidade Católica do Rio Grande do Sul (jose.flores@acad.pucrs.br, jbrfilho@pucrs.br, lucius.samuel@pucrs.br)

Resumo. Este trabalho apresenta resultados de pesquisa em ensino de ciências na formação continuada, modalidade a distância, de professores dos anos iniciais. O objetivo foi analisar as contribuições de uma disciplina do curso de Licenciatura em Pedagogia, orientada metodologicamente pelos princípios do educar pela pesquisa, para as práticas desses professores relacionadas ao ensino de ciências. Também se teve como meta avaliar o fórum de discussões da disciplina como espaço virtual colaborativo de aprendizagem. O material empírico constituiu-se das manifestações postadas pelos professores no fórum de discussão da disciplina. A pesquisa caracterizou-se metodologicamente como de natureza qualitativa, e as interpretações foram realizadas a partir dos pressupostos da Análise Textual Discursiva. Concluiu-se que a disciplina motivou reflexões a partir das trocas de experiências dos participantes relatadas no fórum, o que gerou possibilidades de ressignificação da própria prática pedagógica e ampliou os conhecimentos de ciências e seu ensino.

Abstract. This paper presents results of Science Education research in continuing education, distance learning, of Primary school teachers. Our goal was to analyze the contributions of a course in Pedagogy, methodologically oriented by the principles of education through research, to the practices of teachers related to Science teaching. We also had the objective of evaluating the course forum discussions as a collaborative, virtual and learning space. The empirical material consisted of comments posted by teachers in the course discussion forum. The research was characterized as methodologically qualitative and the interpretations were made from the assumptions of Textual Analysis Discourse. It was possible to conclude that the course motivated reflections from the exchange of experiences among the participants reported on the forum, generating possibilities of reframing their own teaching practice, broadening then their knowledge of Science and teaching.

Palavras-chave: formação docente, ensino de ciências, educação a distância, aprendizagem coletiva Keywords: teacher education, science education, distance learning, collective learning

\section{Introdução}

As críticas que os sistemas educacionais de vários países vêm recebendo em relação à qualidade da educação oferecida têm motivado debates e pesquisas no sentido de encontrar propostas para a melhoria dos processos de aprendizagem e de formação plena das crianças e adolescentes. Dentre os autores que apresentam questionamentos dessa ordem podemos citar: Hernández (1998), na Espanha; Ponte (2004), em Portugal; Gatti (2010), no Brasil. Um dos principais aspectos de tais críticas está voltado para a necessidade de rever os currículos, ainda demasiadamente estruturados sob uma racionalidade técnica na qual o conhecimento é entendido como algo a ser repassado 
aos aprendentes, o que evidencia uma epistemologia empirista-indutivista nas práticas escolares (NÓVOA, 2012; SCHÄFER; OSTERMANN, 2013).

De acordo com as Diretrizes Curriculares Nacionais Gerais da Educação Básica (BRASIL, 2013, p.16), “exige-se, pois, problematizar o desenho organizacional da instituição escolar, que não tem conseguido responder às singularidades dos sujeitos que a compõem”. Salienta esse documento a necessidade de se implementar uma educação que motive os sujeitos a serem criativos, participativos social, política e culturalmente, "capazes de intervir e problematizar as formas de produção e de vida" (idem, p. 16). A esse respeito, vários autores têm se posicionado no sentido de enfatizar a formação de professores como um dos eixos centrais para as mudanças necessárias no ensino (GATTI, 2010; IMBERNÓN, 2011; NÓVOA, 2012). Tanto a formação inicial dos professores quanto a continuada requer novas formas de ação que possam proporcionar aos professores possibilidades reais de tornarem-se protagonistas dessas transformações.

É preciso interromper o círculo vicioso que tem caracterizado a formação de professores, a qual inicia desde sua experiência como aluno - quando são construídas imagens e crenças a respeito da profissão. Esse aluno que opta pela carreira docente, ao ingressar num curso de Licenciatura, já tem uma série de pressupostos e modelos de práticas assimiladas em função de sua experiência desde a infância na escola. Muitas dessas visões de educação correspondem a "estereótipos e esquemas que, em alguns casos, são difíceis de eliminar e superar" (IMBERNÓN, 2011, p. 62). Então, cabe perguntar se a formação inicial tem conseguido proporcionar ao futuro professor condições de problematizar suas concepções de educação a fim de superar certas práticas obsoletas do exercício da profissão. Para Imbernón (2011), a formação inicial deve proporcionar mais do que o acúmulo de conhecimentos e formas culturais préestabelecidas; é necessária uma formação para a atitude investigativa "que considere tanto a perspectiva teórica como prática, a observação, o debate, a reflexão, o contraste de pontos de vista, a análise da realidade social" (p. 64). Os cursos de Licenciatura deveriam ser espaços de formação que motivassem, dentre outros aspectos, a ressignificação do contexto escolar e do fazer docente que pode ser orientado através da pesquisa como fundamento de aprendizagem.

A formação continuada deve caracterizar-se pela prática coletiva de fazer-se professor, incentivando "[...] processos de pesquisa colaborativa para o desenvolvimento da organização, das pessoas e da comunidade educativa que as envolve" (IMBERNÓN, 2011, p. 72). A fim de alcançar que os professores sejam 
capazes de se ajustar às demandas da educação contemporânea, concordamos com Urzetta e Cunha (2013) quando afirmam que a formação continuada deveria ser um espaço de reflexão crítica constante sobre a prática de sala de aula, desenvolvimento da atitude de cooperação e corresponsabilidade, avaliação do trabalho e replanejamento. Significa a predisposição para a revisão de suas ações colocando em questão suas percepções e interpretações numa atitude de escuta dos outros, da realidade. Também supõe o envolvimento com a investigação a partir da elaboração de projetos de trabalho visando à construção do ambiente escolar como comunidade de prática educativa (LAVE; WENGER, 2002).

Uma das lacunas mais significativas e problemáticas que se tem identificado na formação de professores de anos iniciais diz respeito ao precário preparo para desenvolver atividades em ensino de ciências (GATTI, 2010). Neste sentido, vários autores têm salientado a importância de promover nos currículos dos anos iniciais, projetos nos quais as crianças venham a realizar o que alguns autores chamam de alfabetização científica (CHASSOT, 2002; SASSERON, 2008). A formação integral de que falam as Diretrizes Curriculares Nacionais Gerais da Educação Básica (BRASIL, 2013) estará severamente comprometida sem a presença, nos anos iniciais, deste aspecto da cultura que é a ciência (ZANETIC, 2006). O ensino de ciências pode contribuir, juntamente com as outras áreas de conhecimento, para que as crianças desenvolvam compreensões de mundo, de natureza e de si mesmos voltados para o bem social.

A pesquisa que ora é apresentada tem por objetivo analisar as contribuições de uma disciplina sobre ensino de ciências de um curso de Licenciatura em Pedagogia na modalidade a distância, orientada metodologicamente pelos princípios do educar pela pesquisa. Antes de relatar a investigação propriamente dita, serão realizadas algumas considerações a respeito do ensino de ciências nos anos iniciais. Apresentam-se, também, aportes teóricos para o conceito de aprendizagem colaborativa, uma vez que serão analisados os diálogos realizados nos fóruns de discussões da disciplina. Além disso, considera-se necessário discutir os princípios do educar pela pesquisa uma vez que foi o fundamento utilizado para a prática da disciplina considerada nesse trabalho.

\section{Ciências nos Anos Iniciais}

O ensino de ciências nos anos iniciais tem sido foco de vários estudos e debates relacionados ao currículo e à formação de professores, e constata-se que, nos programas de formação desses docentes, pouca ênfase se dá para essa área (RAMOS; ROSA, 2008; 
OVIGLI; BERTUCCI, 2009). Além disso, as poucas horas dedicadas para essa qualificação proporcionam conhecimentos de forma superficial e genérica (GATTI, 2010). Isso contribui para que as crianças venham apenas tardiamente a ter contato com conhecimentos em ciências, o que gera lacunas em relação à cultura científica, e impede que a criança adquira uma percepção mais ampla da realidade. Dessa forma, aprendizados que poderiam ser inseridos já nos primeiros anos de escola, ampliando as possibilidades de compreensão do mundo e da sociedade, são deixados para mais tarde. Perdem-se assim as possibilidades de estimular a curiosidade das crianças em relação aos fenômenos da natureza, e de potencializar suas habilidades cognitivas, o que poderia ampliar sua bagagem cultural e auxiliar na desmistificação da ciência e do trabalho dos cientistas (ZANETIC, 2006).

As demandas da sociedade exigem que as pessoas desenvolvam posicionamento crítico, já que muitas aplicações das pesquisas científicas influenciam de forma direta a vida da população, como a preservação ambiental, o controle da informação, as intervenções genéticas, dentre outros. Sabemos que as ações sobre a natureza devem ocorrer de modo responsável, a fim de que a vida seja sempre a prioridade, e que as decisões sobre os usos dos espaços naturais devem atender às demandas da coletividade. Ainda persiste, em nossa sociedade, a concepção de que a ciência é uma fonte de informação de total confiança, e que os cientistas têm autoridade absoluta (SASSERON, 2008). Isso tem levado os setores da sociedade a delegar decisões, de forma pouco crítica, às instituições científicas.

Diante dessa realidade, a educação passa a ter, cada vez mais, papel fundamental na formação de cidadãos conscientes e comprometidos com o bem social. Assim, o ensino de ciências deve estar presente desde os primeiros contatos da criança com a escola (CHASSOT, 2002). Isso não significa, necessariamente, que devam ocorrer discussões que envolvam aspectos políticos, econômicos e sociais a respeito da área científica nos anos iniciais. Mas devem existir ali vivências investigativas, estímulo da curiosidade, incentivo e valorização da pergunta bem como a proposição de atividades de caráter científico (SASSERON, 2008).

Algumas das justificativas que se têm apresentado para o desenvolvimento de estudos científicos com as crianças nos anos iniciais estão direcionadas para compreensões de que tais aprendizados servirão para seus futuros estudos nas ciências em anos subseqüentes. Hernández (1998) sustenta que essa compreensão está ancorada na ideia de que a finalidade da infância é chegar à vida adulta e discorda dessa tese 
afirmando que devemos transgredir “[...] essa visão da escola que impede que os alunos se construam como sujeitos em cada época de sua vida" (p. 13). Dessa forma, rejeitamos a noção de que alfabetização científica seja caracterizada como algum tipo de preparação. Ao contrário, defendemos que alfabetização científica corresponde a desafios que se integram a outras ações de descobertas e são necessárias para que o aluno construa suas formas de entender e vivenciar os espaços sociais, a natureza e a si mesmo. Lembramos a sempre atual afirmativa de Madalena Freire (1983, p. 15): "quando se tira da criança a possibilidade de conhecer este ou aquele aspecto da realidade, na verdade se está alienando-a da sua capacidade de construir seu conhecimento".

O ensino de ciências nos anos iniciais necessita receber maior atenção na estruturação dos currículos e nas práticas formativas nos cursos de graduação em licenciaturas. O modelo de conhecimento fragmentado e desconectado da realidade ainda permanece com influência marcante na vida dos professores de anos iniciais. É provável que suas concepções sobre o ensino de ciências remontem aos aprendizados realizados durante sua formação básica na qual os conhecimentos científicos, ainda hoje são apresentados como objetos estáveis e universais (SASSERON, 2008). Por isso, é natural que professores formados em Licenciatura em Pedagogia apresentem algumas lacunas ou desvios conceituais referentes a fenômenos físicos, químicos e biológicos, o que acarreta insegurança no sentido de realizar atividades em áreas científicas com as crianças.

A formação do indivíduo em sua integralidade, proposta nas Diretrizes Curriculares Nacionais Gerais da Educação Básica (BRASIL, 2013), “[...] significa potencializar o ser humano como cidadão pleno, de tal modo que este se torne apto para viver e conviver em determinado ambiente, em sua dimensão planetária” (p. 16). Acrescenta ainda esse documento que a escola precisa ser reinventada direcionando suas ações para a realização de processos capazes de motivar os sujeitos para a participação colaborativa, de forma criativa, visando mudanças no contexto social.

Para se atingir essa plenitude e compreensão de si mesmo como ser do mundo e no mundo é necessário que o ensino de ciências esteja presente desde os anos iniciais, contribuindo para proporcionar à criança a ampliação das possibilidades de perceber-se capaz de atuar nessa realidade e sentir-se comprometido com seu espaço social (SASSERON, 2008). Conforme Hernández (1998) há que se propor os conhecimentos científicos “[...]como realidades socialmente construídas que, por sua vez, reconstroem- 
se nos intercâmbios de culturas e biografias que têm lugar na sala de aula" (p.12). Mas, para que se desenvolvam atividades educativas com esses fins, é necessário que o professor esteja realizando em si mesmo esse processo de formação científica, integrando as áreas de conhecimento e entendendo a ciência como mais um aspecto da cultura, elaborada coletivamente.

A ciência vista com o enfoque que defendemos, de caráter histórico e culturalmente contextualizada, vem acompanhada pelo questionamento da verdade, da objetividade e "das visões unilaterais que impõem um único ponto de vista de interpretação de um fenômeno" (HERNÁNDEZ, 1998, p. 28). O professor é desafiado, portanto, a trabalhar a partir de um enfoque interpretativo e compreensivo da realidade, permitindo aos alunos maior liberdade de expor suas dúvidas e elaborar hipóteses explicativas.

Esses aspectos concernentes à formação continuada dos professores requerem das instituições a geração de ações integradas de reflexão, de pesquisa e problematização. O ambiente escolar necessita ser construído como espaço coletivo de aprendizados, pois como aspecto da prática social, a aprendizagem envolve a pessoa inteira; implica não somente uma relação com atividades específicas, mas uma relação com comunidades sociais (LAVE; WENGER, 2002).

Como o material empírico da pesquisa aqui relatada foi coletado a partir do fórum de discussões de um curso de licenciatura na modalidade a distância, considerase adequado analisar alguns aportes teóricos a respeito do que vários autores têm chamado de espaços colaborativos de aprendizagem.

\section{Espaços colaborativos de aprendizagem}

Os espaços colaborativos de aprendizagem têm sido objeto de estudo de vários pesquisadores da educação a fim de enfatizar que o trabalho coletivo traz resultados mais amplos e mais profundos do que quando se desenvolvem projetos de ensino individualmente (LEVY, 1996; HERNÁNDEZ, 1998; LAVE; WENGER, 2002). Esses autores estabelecem sua compreensão de aprendizagem a partir de uma perspectiva social; ou seja, é na prática coletiva que são construídas as percepções, interpretações e significados sobre a realidade. Um dos destaques da teoria de Lave e Wenger (2002) diz respeito à concepção epistemológica que propõe a aprendizagem como uma experiência de conhecimento. A partir desse enfoque os autores pretendem criticar a visão dualista de mundo que "[...] tem mantido as pessoas reduzidas a suas mentes, processos mentais 
a racionalismo instrumental, e a aprendizagem à aquisição de conhecimento" (LAVE; WENGER, 2002, p. 168). Assim, os autores defendem uma teoria da prática social cuja ênfase encontra-se na interdependência relacional de agente e mundo, na construção de significados de forma social e intersubjetiva. "Esta visão também afirma que aprender, pensar e saber são relações entre pessoas em atividade no mundo, com o mundo e surgidas do mundo socialmente e culturalmente estruturado" (idem, p. 168). Justificam, os autores, sua teoria segundo a qual as comunidades de prática correspondem a espaços onde a aprendizagem se concretiza de forma compartilhada. Nessa perspectiva, a participação no coletivo corresponde à construção de significados de forma negociada, e o entendimento e as experiências estão em constante interação. Vale destacar a seguinte afirmativa dos autores:

\footnotetext{
A noção de participação, assim, dissolve dicotomias entre atividade cerebral e corporal, entre contemplação e envolvimento, entre abstração e experiência: pessoas, ações e o mundo estão implicados em todo o pensar, falar, conhecer e aprender. (LAVE; WENGER, 2002, p. 169)
}

A formação continuada, confirmando nossas experiências educativas e em consonância com outros autores (FREIRE, 1981; DEMO, 2002; IMBERNÓN, 2011; URZETTA; CUNHA, 2013), deve ser realizada como processo coletivo no ambiente escolar. As ações reflexivas em espaços colaborativos geram interações e diversificam as possibilidades didáticas numa constante problematização das práticas. Em um curso de formação a distância, mesmo considerando alguns momentos presenciais, o espaço de encontro sistemático é o fórum de discussões. Por isso, nosso interesse em verificar as reais possibilidades de esse espaço representar um ambiente de socialização de pesquisas, dúvidas, sugestões e aprendizados a partir do contato com professores, tutores e colegas.

A educação a distância é uma modalidade de ensino que tem recebido grande atenção por parte de pesquisadores no Brasil, pois as tecnologias digitais de comunicação propiciam cada vez maior qualidade e rapidez nos acessos e interações via internet. Isso tem gerado maiores possibilidades de pesquisas e trocas de experiências por meios eletrônicos. Dadas essas características, tornam-se evidentes as possibilidades de esses recursos cada vez mais serem agregados como apoio metodológico nas práticas de ensino nas escolas e universidades.

De acordo com Belloni (2002), a realidade virtual encontra-se presente na vida diária de professores e estudantes, fazendo parte de seus universos de socialização, e 
não pode ser desconsiderada pelas instituições educacionais quando elaboram seus Projetos Político-Pedagógicos. Segundo a mesma autora, a educação a distância já é um fenômeno caracterizado como parte da inovação em que a integração das tecnologias passa a influir nos processos de ensino e de aprendizagem.

Em um contexto de educação a distância, os fóruns de discussões exercem papel importante como ambiente de comunicação e troca de experiências. Bastos et al. (2005) defendem essa ferramenta como mais uma instância de formação em que são valorizados os ambientes de aprendizagem coletiva. Os aspectos colaborativos que o fórum de discussões oferece possibilitam a interação e trocas de experiências, além da pesquisa sobre as próprias compreensões, gerando novas formas de interpretar a realidade educacional, assim, "a formação mediada por esses recursos, numa abordagem dialógico-problematizadora, pode mobilizar saberes da docência fazendo com que sejam críticos e investigadores de sua prática e com capacidade de avaliação" (BASTOS et al, 2005, p. 2).

O fórum, entendido dessa forma, apresenta-se como campo de investigação no qual o questionamento reconstrutivo "[...] oferece a base da consciência crítica e a alavanca da intervenção inovadora" (DEMO, 2002, p. 11). Esse espaço constitui-se como possibilidade de diálogo onde os sujeitos elaboram as significações relacionadas ao seu fazer educativo. Também surge como ambiente privilegiado para as construções e descontruções, trocas de opiniões, debates e argumentações (BARROS; SOUZA, 2011). Todo pensar e escrever são processos interativos. As nossas faculdades mentais são exercidas em função da comunidade em que vivemos, com suas heranças, conflitos e planos (LEVY, 1996). Nesse ambiente, portanto, podem-se promover reflexões dialógicas sobre o que cada professor realiza e pensa, tornando-se parte integrante, e necessária, das pesquisas sobre suas práticas. A pesquisa torna-se o campo privilegiado de formação de professores.

\section{Educar pela pesquisa na formação docente}

Vários estudos têm demonstrado a deficiência nos programas das instituições formadoras no que tange à qualificação de professores nos anos iniciais, em especial na área de ciências da natureza (RAMOS; ROSA, 2008; OVIGLI; BERTUCCI, 2009; GATTI, 2010; AZEVEDO; ABIB, 2013). Sendo assim fica evidente a necessária reorientação dos programas de formação de professores a fim de engendrar mudanças significativas. Com o intuito de buscar propostas que apresentem novas possibilidades 
de formação, pesquisadores têm sugerido a investigação como metodologia de trabalho. Neste sentido de enfoque temos encontrado na literatura uma polissemia de expressões que se aproximam em suas elaborações conceituais, dentre elas citamos: projetos de trabalho (HERNÁNDEZ, 1998), educar pela pesquisa (DEMO, 2002), modelo indagativo (IMBERNÓN, 2011). O que se encontra de comum nesses autores, além de outros aspectos, é o questionamento ao modelo transmissivo, individualizado e fragmentado do conhecimento pautado numa racionalidade técnica.

Hernández (1998) destaca que o melhor caminho para aprender a pensar é a pesquisa, através da qual se colocam em questão as crenças e certezas para a possibilidade de interpretar a realidade a partir da produção de novos significados compartilhados e não dogmáticos. Enfatiza esse autor, a atitude de pensar por si mesmo, a relação educativa baseada na colaboração com a comunidade "[...] onde a paixão pelo conhecimento seja a divisa e a educação de melhores cidadãos o horizonte ao qual se dirigir" (HERNÁNDEZ, 1998, p.13).

Pedro Demo (2002) propõe a pesquisa como a única forma de aprendizado e acredita que por essa via se possa resgatar o papel do professor, argumentando que a pesquisa incorpora necessariamente a prática ao lado da teoria e assume marca política do início até o fim. O professor que se engaja na pesquisa sobre si mesmo e sobre seu fazer amplia sua capacidade crítica e criativa, e essa atitude será a sua proposta de trabalho, desafiando seus alunos a serem construtores de si mesmos. O conhecimento, adquirido pela investigação, torna-se uma ferramenta poderosa de inovação, através da qual o sujeito pode "fazer e se fazer oportunidade histórica" (HERNÁNDEZ, 1998, p. 7).

Para Imbernón (2011) o modelo indagativo refere-se à capacidade de o professor elaborar questões sobre sua prática e de estabelecer objetivos que tratem de responder a tais questões. Quando o professor é desafiado a fazer suas próprias perguntas e buscar elementos para respondê-las, acaba por encontrar novas formas de compreensão. Como essas indagações estão relacionadas com a procura de repostas para os problemas da escola e da sala de aula, a pesquisa se realiza de forma cooperativa. Segundo Imbernón (2011), quando decidem por serem pesquisadores, “[...] os professores colaboram mais uns com os outros aprendendo a serem professores melhores sendo capazes de transcender o imediato, o individual e o concreto" (p.81).

Esses autores ressaltam o caráter político, coletivo e colaborativo que a pesquisa enseja, pois permite a participação de forma integrada, sendo enriquecida pelas 
vivências que cada um traz de suas experiências e reflexões. A pesquisa, portanto, promove não só a integração de áreas na própria escola, mas também a interação com seu entorno (MANFREDO, 2006). É o que também afirmam as Diretrizes Curriculares Nacionais Gerais da Educação Básica (BRASIL, 2013, p. 164): "Se a pesquisa e os projetos objetivarem, também, conhecimentos para atuação na comunidade, terão maior relevância, além de seu forte sentido ético-social”.

Essas breves considerações a respeito da pesquisa na educação demonstram, além de outros aspectos, que tal metodologia incentiva construção de ambientes colaborativos de aprendizagem tornando-se elemento fundamental para a constituição de comunidades de prática (LAVE; WENGER, 2002).

\section{Relato da pesquisa e análise das ações}

Os relatos e análises que seguem visam a trazer reflexões que possam contribuir com os debates e pesquisas que têm sido realizadas em âmbito nacional e internacional a respeito das urgentes mudanças na educação. A experiência pedagógica de formação docente na modalidade a distância aqui descrita revela uma caminhada dos pesquisadores, autores deste artigo, no sentido de identificar fatores que demonstrem a possibilidade de novas formas de propor as práticas educativas. Acredita-se numa educação que proporcione o desenvolvimento de pessoas competentes, conscientes e comprometidas com seu mundo e sua sociedade buscando a realização de justiça social.

A seguir, apresentam-se os relatos e análises.

\section{Procedimentos metodológicos}

Esta pesquisa desenvolveu-se a partir de uma experiência de formação continuada de professores através de uma disciplina na área de ciências no curso de Licenciatura em Pedagogia, modalidade a distância, da Universidade Federal do Rio Grande do Sul (UFRGS). Tal curso, com duração de quatro anos, visava à qualificação em nível superior de professores em atividade na rede pública, que serão denominados a partir de agora de alunos-professores. Portanto, para esses alunos-professores, o curso poderia ser caracterizado em nível de formação continuada e atendeu pólos situados em cinco municípios diferentes, próximos a Porto Alegre-RS. Em cada polo estavam matriculados 80 alunos-professores no início do curso. A disciplina foi chamada de Representações do Mundo pelas Ciências Naturais e ocorreu no quarto semestre. Cada polo tinha um professor da área de ciências (química, física e biologia) e dois tutores. A 
pesquisa foi realizada com alunos-professores de um dos polos em que o professor é um dos autores deste artigo.

Neste trabalho as palavras "alunos-professores" e "alunos" designam, indiferentemente, sujeitos tanto do sexo masculino quanto feminino. A seguir, a descrição das atividades propostas.

\section{Atividades propostas na disciplina}

A disciplina foi organizada em quatro módulos. Nossa análise foi realizada a partir do módulo 1: Concepção de natureza: relação ser humano e ambiente. Na atividade presencial, no início do semestre, foi entregue uma folha de papel tamanho A4 na qual inserimos um quadro com dezesseis subdivisões iguais. Em cada subdivisão colocamos, na parte superior, uma palavra. Cada aluno-professor deveria desenhar o que aquela palavra lhe sugerisse. As palavras foram as seguintes: luz, árvore, estrada, força, raiva, átomo, pé, água, ácido, saudade, coração, micróbio, céu, célula, planeta, energia. Tais palavras foram indicadas pelo grupo de tutores da disciplina de forma aleatória, procurando-se contemplar aspectos que sugerissem conceitos científicos e expressão de sentimentos. Na semana seguinte foi pedido que os alunos-professores realizassem essa mesma atividade com seus alunos. Na biblioteca virtual, foi postada por um dos tutores uma poesia de Jayme Caetano Braun (1996) intitulada "Coruja do Campo", além de dois artigos, um tratando do ensino de ciências e outro das representações de natureza na mídia. Os alunos-professores deveriam postar no fórum de discussões da disciplina suas observações a respeito das interpretações sobre os desenhos, os textos sugeridos e a poesia. Os textos sugeridos foram os artigos de Amaral (1997) e Rosa e Oliveira (1999).

A opção por essas estratégias na fase inicial da disciplina atendeu às orientações pedagógicas do curso no sentido de propor aos alunos-professores atividades que pudessem ser trabalhadas em suas práticas com as crianças. Com essas atividades também se pretendeu promover atitude investigativa desses alunos-professores a respeito de suas próprias ações docentes, motivando-os a realizar perguntas sobre seu fazer pedagógico, sobre seus próprios conceitos de natureza e o ensino de ciências.

A investigação foi realizada com 29 alunos-professores, que denominamos de AP seguido por número de 1 a 29. Assim, os alunos-professores foram indicados como AP1 até AP29. Dos mais de setenta matriculados no polo, foram esses 29 alunosprofessores que realizaram postagens no fórum. A metodologia utilizada foi de caráter 
qualitativo, sendo os registros extraídos a partir das postagens realizadas pelos alunosprofessores no fórum de discussões da disciplina, na plataforma ROODA ${ }^{1}$.

A interpretação do material escrito apoiou-se nos fundamentos da Análise Textual Discursiva (ATD) proposta por Moraes e Galiazzi (2011). Foi organizada uma tabela com os textos, de forma a ser possível visualizar de forma panorâmica as manifestações, comparando-as e buscando aproximações conceituais. Para a análise do material escrito, procedemos à sequência recursiva, em seus três passos: desconstrução dos textos do corpus, unitarização e categorização (MORAES; GALIAZZI, 2011). Após realizar esses passos, emergiram categorias, que denominamos: a) tomada de consciência sobre a própria prática; b) novas práticas de aprendizado sobre a natureza e ensino de ciências; c) a arte no ensino de ciências; e d) formação a partir de práticas colaborativas. Para Moraes e Galiazzi (2011), a categorização corresponde ao processo de aprendizado sobre os fenômenos investigados bem como à comunicação das aprendizagens. Essa última etapa da ATD concretiza-se na produção deste artigo.

Apresentamos a seguir cada uma das categorias emergentes.

\section{Tomada de consciência sobre a própria prática}

As atividades suscitaram nos alunos-professores movimentos de análise sobre si mesmos e suas práticas em relação a noções de natureza e ensino de ciências. As manifestações demonstram percepção de conceitos adquiridos e assumidos de forma irrefletida, como se pode constatar nos comentários de alguns alunos-professores:

\footnotetext{
AP2 - Sou do tempo em que na escola não se abria a boca para perguntar nada, muito menos dar alguma sugestão, se tentasse levava castigo. Não se tinha direitos, só deveres. Hoje, vejo que pouco mudou, pois ainda encontramos 'profissionais' agindo da mesma forma com seus alunos.

AP5 - Este trabalho nos leva a refletir sobre o que nós recebemos pronto, não questionamos e passamos para nossos alunos como verdades absolutas. AP10- [...] recebemos algo pronto e apenas repassamos um modelo que anteriormente já foi no passado quando éramos alunos do Ensino Fundamental.

AP15 - Estamos condicionados a repetir, repetir o que nos é passado sem pensar, sem questionar.

AP21 - Esta atividade nos leva a pensar sobre crenças, preconceitos, hipótese, o que é real, o que é verdadeiro ou não.
}

Percebe-se nas narrativas um processo reflexivo sobre a própria formação. Um olhar histórico sobre si mesmo (AP2- sou do tempo...), gerando análises que auxiliam no caminho do autoconhecimento. Enquanto se descobre como ser constituído cultural e

\footnotetext{
${ }^{1}$ Ambiente virtual de aprendizagem desenvolvido pelo CINTED/UFRGS.
} 
historicamente, é capaz de tornar suas lembranças objetos de análise e reflexão. Esse movimento de retorno ao passado revela a capacidade de perguntar pela sua origem e seu destino (AP21- esta atividade nos leva a pensar...). Essa trajetória em busca de compreensão de como chegou até este momento de sua vida corresponde a um começo de ressignificação de si mesmo e, consequentemente, de sua atividade profissional.

As manifestações revelam constatações desses alunos-professores de que, quando estudantes (na escola básica ou magistério), seu ensino tinha características transmissivas e reprodutivistas (AP15 - condicionados a repetir), e que essa forma de ensino a que foram submetidos trouxe consequências que repercutem em suas visões de natureza e em suas práticas docentes atuais (AP10 - apenas repassamos um modelo). $\mathrm{O}$ fato de realizarem essas afirmações caracteriza um movimento de inconformidade com sua forma de trabalhar e com os resultados de sua prática. Essa atitude é fundamental para se iniciar um processo de transformação e busca de novas compreensões sobre si mesmo e, consequentemente, sobre seu fazer diário em aula. Também aqui se revela uma importante característica do aprendizado por investigação, apresentado por Demo (2002):

\begin{abstract}
A pesquisa inclui sempre a percepção emancipatória do sujeito que busca fazer e fazer-se oportunidade, à medida que começa e se reconstitui pelo questionamento sistemático da realidade [...] Nesse horizonte, pesquisa e educação se confundem, ainda que, no todo, uma não possa reduzir-se à outra. (DEMO, 2002, p.8)
\end{abstract}

A ação de pesquisar auxilia na tomada de consciência sobre a própria prática e não se caracteriza apenas por processos externos ao sujeito que visa modificar as ações de sala de aula. Essa tomada de consciência ocorre a partir de movimentos reflexivos voltados para questionar compreensões que o professor possui a respeito de si mesmo, interpretações que realiza sobre o mundo, sobre a sociedade, sobre a educação e sobre sua interação com os alunos. A realidade que necessita ser transformada passa pelo desconforto e pela inquietação que determinadas circunstâncias causam. Segundo Imbernón (2011) a reflexão sobre as próprias práticas possibilita o exame das teorias implícitas e os esquemas de funcionamento que direcionam a ação do professor. Isto exige um processo permanente de autoavaliação, de investigação de si mesmo, ou seja, de autoconhecimento. Por isso a pesquisa deve estar presente em toda a ação pedagógica - a pesquisa temática, a pesquisa sobre os alunos, a pesquisa sobre o ambiente e a pesquisa sobre si mesmo. Esse movimento interior ficou explícito a partir das atividades de desenhos que os alunos-professores produziram durante o encontro 
presencial. Suas interpretações gráficas não estão desvinculadas de suas visões sobre o mundo, de suas histórias de vida, de suas formações acadêmicas, de suas simbologias inconscientes, dos aspectos psicológicos como emoções e afetos. Vejamos algumas revelações dos alunos-professores:

\begin{abstract}
AP1 - [...] realizei não só com os alunos e alguns colegas de escola a atividade dos desenhos. Mas me fez refletir muito sobre as minhas aulas.

AP4 - Este trabalho foi realmente incrível, pois despertou em mim a identificação do quanto temos ideias pré-determinadas sobre certos elementos.

AP12 - No meu tempo de estudante esta disciplina era desenvolvida da mesma forma que ainda persiste na maioria das escolas, sem questionar e investigar o que ocorre na natureza. Como foi difícil para mim no primeiro momento representar em figuras as palavras sugeridas. Esta dificuldade é o resultado de não ter podido refletir sobre os assuntos apresentados no meu tempo de estudante.

AP28 - A começar pela atividade inicial, bastante inesperada, mas de recursos incríveis. Através dela pude fazer várias observações tanto em mim como nos meus discentes.
\end{abstract}

Ao desenhar e comparar seus desenhos com os demais colegas os alunosprofessores ficaram surpresos com as semelhanças de cada figura. Desenhos com padrões muito próximos de representação, como a árvore, que todos desenharam praticamente no mesmo formato, levaram a autocríticas como as mostradas acima. As representações gráficas revelam o quanto o contexto interfere nos processos de aprendizagem e como a consciência está vinculada a interações com o social e o histórico. Nesta experiência ficam manifestos os resultados de uma formação básica e profissional realizada de forma massificada e estandardizada. Segundo Lave e Wenger (2002) a prática social enfatiza a interdependência de agente e mundo, atividade, significado, cognição, aprendizagem e conhecimento. Neste caso, a prática demonstra o quanto esses alunos-professores sentem-se cerceados pelos próprios condicionantes de sua história de formação acadêmica.

Após a realização das atividades com desenhos, foram sugeridos dois textos, indicados anteriormente, postados pelos tutores. O intuito foi o de, além de provocar a análise crítica de sua prática docente, também apresentar material que auxiliasse os alunos-professores nesse processo de reflexão.

Num dos textos sugeridos, o de Rosa e Oliveira (1999), encontram-se questionamentos importantes sobre a construção do conhecimento científico ao longo da história e de como a escola, no ensino de ciências, tem se pautado em uma única forma de interpretação da natureza. Essa visão ainda se encontra presente em nossos ambientes escolares, onde é ensinado como "o conhecimento" e não como "um 
conhecimento". Rosa e Oliveira (1999) chamam a atenção para a necessidade de estarmos abertos para a diversidade de formas de ver o mundo e de visões alternativas de interpretações sobre os fenômenos da natureza. O professor que percebe esse contexto estará mais atento às concepções e pensamentos de seus alunos. As autoras recomendam a visão histórica das ciências que o professor precisa ter, pois isso the permitirá verificar a provisoriedade das verdades científicas. Esses elementos levarão o professor a questionar seus próprios entendimentos e visões sobre a ciência e o auxiliarão a perceber em que pressupostos epistemológicos as suas compreensões estão fundamentadas.

O texto de Amaral (1997) traz aspectos de sua pesquisa de mestrado mostrando como as representações de natureza podem estar permeadas por interpretações que a mídia nos apresenta, cujo objetivo principal é o aumento do consumo. Alerta para a importância de os educadores estarem atentos para as políticas de representação da natureza engendradas pelos meios de comunicação. Afirma também que a escola e a mídia continuam a nos oferecer ideias de natureza objetificada, sujeita à exploração e dominação. Sobre estes textos apresentamos alguns comentários de alunos-professores:

AP15 - Os textos lembraram-me do poder fantástico que a mídia tem, de condicionar, de atribuir ideias, de muitas vezes alienar, mesmo quando pensamos que estamos sendo informados, por que nos informam o que convém, o que querem. Percebo que muito tenho para mudar nas minhas aulas.

AP1 - Sempre tentei renovar minhas aulas de Ciências, mas lendo os textos fiquei com vergonha de minhas aulas.

AP12 - Ao ler e refletir sobre os textos sugeridos, fiquei analisando o quanto ainda precisamos aprender sobre a representação do mundo pelas ciências naturais.

A crítica que os textos propuseram auxiliou no processo reflexivo de questionar as próprias compreensões, os modos de entendimento da natureza e como ensinar ciências. As teorizações apresentadas pelas autoras Rosa e Amaral proporcionaram um caminho explicativo para que os alunos-professores pudessem analisar suas práticas. Através da confrontação entre as reflexões apresentadas nos textos e suas ações foi possível uma experiência de questionamento reconstrutivo (DEMO, 2002). Segundo Demo (2002) é sumamente importante conduzir o processo de aprendizagem como evolução teórica e prática, pois assim a problematização mantém-se vinculada à vida real. Imbernón (2011) enfatiza a necessidade de construção de novos conceitos para que se possam realizar mudanças e isso supõe romper certas inércias e ideologias institucionais que ainda perduram. As revelações dos alunos-professores indicam esta 
vontade de ruptura com situações que os deixam insatisfeitos com o próprio fazer profissional. Manifestam, dessa forma, que desejam encontrar novas práticas, como podemos verificar na próxima seção.

\section{Novas práticas de aprendizado sobre a natureza e o ensino de ciências}

As reflexões anteriores indicam posicionamentos e desejos de mudança por parte dos professores. Ao tomarem consciência de que suas compreensões e formas de encaminhar suas aulas não incentivavam seus alunos ao aprendizado, passaram a pensar em novas formas de propor atividades a seus alunos e em ações pedagógicas voltadas para o protagonismo de seus alunos enquanto aprendizes. Vejamos algumas manifestações:

\footnotetext{
AP4 - Nos serve de alerta para começarmos a mudar nossa forma de trabalhar os elementos naturais. Devemos ver mais, pensar mais sobre eles e apresentar menos modelos deles.

AP7 - A partir do seu planejamento, propor atividades que estimulem a reflexão e a ação. Proporcionar momentos de planejamento e pesquisa dentro da sala de aula.

AP12 - [...] dar aos meus alunos maior espaço para análise dos conceitos científicos ampliando sua criticidade sobre o assunto.

AP18 - Hoje observo como é importante averiguarmos os conhecimentos que nossos alunos já trazem. Também vejo que às vezes abordamos conceitos tão distantes e abstratos para as crianças.

AP20 - Será que estamos passando a eles aspectos que os façam refletir sobre seu papel no mundo em que vivem, mudando a visão de apropriação da natureza como um bem inesgotável e equilibrado? Sabemos que temos que iniciar uma nova fase, instruir, resgatar e alertar sobre a realidade, sobre o equilíbrio da natureza e a relação do homem com a mesma.
}

Essas citações dos alunos-professores evidenciam a atitude de questionar certezas e desejar o diferente; mostram que estão dispostos a refletir sobre sua prática na ação. Isso significa estar atentos ao que o aluno faz e diz, buscando compreendê-lo em suas dúvidas e formas de se expressar (AP12 - dar aos meus alunos maior espaço para análise dos conceitos científicos ampliando sua criticidade sobre o assunto); não ter pressa em dar respostas para as dúvidas do aluno, mas ser capaz de parar, mostrar que está pensando sobre o que ele disse ou escreveu, evitar uma resposta pronta; permitir-se ser surpreendido; olhar com atenção para os saberes e as vivências que o levaram a elaborar determinada pergunta (AP18 - é importante averiguarmos os conhecimentos que nossos alunos já trazem). Os alunos-professores, a partir dessas constatações, percebem novas formas de propor atividades e passam a ter maior confiança que podem fazer diferente ao vislumbrar o aprendizado de seus alunos (IMBERNÓN, 2011). Por realizarem autocrítica sobre as próprias representações de natureza e o ensino de 
ciências podem pensar em novas práticas que ampliem a atitude questionadora e investigadora de seus alunos. Após realizarem os desenhos na aula presencial e lerem o poema, perceberam que é possível se apoiar em estratégias relacionadas com atividades artísticas para ampliar os recursos pedagógicos de forma criativa. Analisa-se mais de perto este aspecto a seguir.

\section{A arte no ensino de ciências}

A escuta da poesia despertou surpresa em alguns alunos-professores por ser uma forma inusitada para uma aula de ciências. Fez refletir o quanto se podem explorar outras estratégias e romper com princípios educacionais pautados na compartimentalização de conhecimentos. Deve-se considerar a ciência como mais um elemento da cultura, e não como um conhecimento desvinculado do próprio contexto social (ZANETIC, 2006).

Não só o conteúdo, mas a forma de apresentação de um tema científico, por meio de uma poesia, gerou nos alunos-professores reações no sentido de perceberem relações entre ciência e poesia. A partir dessa experiência foi possível provocar os alunos-professores para a abertura a novas compreensões e relações que podem ser feitas num processo de descrever a realidade e as descobertas sobre si mesmo. Abaixo algumas manifestações:

\footnotetext{
AP18 - Que interessante esta maneira de encarar a introdução de temas científicos com nossos alunos.

AP24 - Li a poesia e adorei, faz com que nós paremos para pensar, refletir sobre as crendices de nossa infância, que alguns ainda levam para a vida adulta.

AP5 - Essa poesia nos faz pensar sobre significados que nos foram passados na infância e que nós por nunca termos analisado, observando com um olhar diferente, carregamos até hoje, imagem de coisas e fatos que se constituíram em nossa mente de forma errada.
}

O currículo no qual se propõe a formação de pessoas em sua plenitude deve oferecer vivências e experiências em que e o aluno pode sentir-se autor de suas conclusões e conjecturas a respeito da realidade. A partir dessa perspectiva epistemológica, a educação para a sensibilidade artística ganha importância fundamental. A criatividade humana, segundo Ostrower (1987), é um fator determinante na percepção de si mesmo já que, enquanto cria, o sujeito realiza-se e transforma-se. Para essa autora, a sensibilidade representa uma abertura constante ao mundo e nos liga de forma direta ao que acontece em torno de nós (OSTROWER, 1987). Neste sentido, ciência e arte imbricam-se como elementos que podem superar a disciplinarização dos 
conhecimentos para a interpretação da realidade. A arte, quando inserida como um dos processos criativos de elaboração de teorias, proporciona flexibilidade e abertura à novidade, oferecendo àquele que pesquisa possibilidades de ser surpreendido pelo que observa e pergunta. Para Ostrower (1987), a filosofia racionalista e reducionista que tem sido dominante nos currículos aliena o sujeito de si mesmo, de suas potencialidades criativas e o impede de realizar conteúdos mais humanos. A ação de desenhar e escutar a poesia levou os alunos-professores a vivenciarem uma estratégia didática na qual puderam exercer sua capacidade interpretativa e de criação, conduzindo-os a autoanálises. É o que foi possível constatar nos excertos abaixo:

\footnotetext{
AP26 - Percebi o quanto pode ser provocativamente boa uma aula onde se ouve música para falar do ciclo da água, se desenha para falar de sentimentos, formas da natureza e iniciação científica.

AP21 - Considero a atividade dos desenhos fantástica, ao mesmo tempo em que é uma atividade extremamente simples e fácil de ser realizada, é também muito rica em conteúdos e dela podemos abrir um leque de propostas de trabalho.

AP29 - Começar a primeira aula de ciências com representações de palavras através de desenhos foi muito interessante, a maneira como nos foi proporcionado pensar em certos conceitos através desta representação tornou a aula agradável.

AP18 - Realmente nossas atividades de ciências estão nos fazendo refletir muito. Como é importante averiguarmos os conhecimentos que nossos alunos já trazem dos conteúdos que serão trabalhados.
}

A experiência descrita e os depoimentos dos alunos-professores evidenciam como é possível tratar de temas científicos envolvendo a diversidade de interações com o mundo, favorecendo a ampliação de relações e construção de significados mais amplos. Além de conceitos científicos, também entram em questão os aspectos emocionais e afetivos compondo o aparato interpretativo que os seres humanos dispõem.

Os alunos-professores foram desafiados a realizar reflexões que revelaram aspectos sobre sua prática, sobre suas crenças, sobre suas dificuldades pedagógicas (AP18-[...] é importante averiguarmos os conhecimentos que nossos alunos já trazem). Foi possível perceber que atividades envolvendo expressões artísticas propiciam a revisão dos próprios conceitos a partir de outras perspectivas (AP-29 pensar em certos conceitos através desta representação), tornando-se, dessa forma, fortes aliadas na pesquisa a respeito da ação pedagógica e de si mesmo. Os alunos-professores percebem que essas práticas, além de poderem tratar de temas importantes da ciência e da natureza, propiciam que isso seja feito de forma prazerosa (AP29 - tornou a aula agradável). 
Percebe-se, além disso, a possibilidade de manifestar suas idéias dialogando com o grupo, com os outros professores. Ao procurar escrever sobre suas compreensões a respeito das atividades os alunos-professores exercem, através do diálogo, uma ação importante para o aprofundamento de suas reflexões. Aqui aparece mais uma dimensão do processo reflexivo e problematizador, tão importantes para a atitude investigativa: a narração de si mesmo para o outro e a construção coletiva.

\section{Formação a partir de práticas colaborativas}

As atividades propostas, como foi possível constatar, motivaram os alunosprofessores a reflexões sobre suas práticas docentes examinando teorias implícitas que conformam seu modo de ver a realidade. Os alunos-professores manifestaram insatisfação com suas ações ao não conseguirem mobilizar os alunos para aprendizados significativos em ciências. Ao examinarem suas atividades e as próprias visões sobre ciências e seu ensino, realizaram questionamentos reconstrutivos, perguntaram-se sobre novas formas de proceder em sala de aula e puseram-se em atitude de querer mudanças.

Contudo, esses processos reflexivos e avaliativos dos alunos-professores ocorreram de forma mais intensa e profunda por se sentirem participantes de um grupo que se integra a partir de objetivos comuns. Ao perceberem afinidades em suas práticas educativas sentiram-se motivados a trocas de experiências expondo suas dificuldades e incertezas ao mesmo tempo em que manifestavam vontade de fazer diferente. Esse sentimento de pertencer a uma coletividade fica claro na forma como se expressam e se dirigem uns aos outros, conforme podemos perceber:

AP1 - Temos muitas coisas a discutir e penso que um semestre é pouco para tantas ansiedades.

AP7 - Achei muito interessante a fala da minha colega J.: "Fomos acostumados a seguir um planejamento imposto por alguém que não sei quem".

AP7 - M., com relação a tua colocação, acredito que o educador precisa conhecer a realidade e o entorno social em que a escola está inserida.

AP7 - Olá! Hoje postei um texto no blog, sobre Paulo Freire, que está ligado a nossa discussão sobre curiosidade, fazer diferente, questionar e questionarse.

AP7 - Todas as questões colocadas neste Fórum demonstram a preocupação e consciência de que é preciso mudar.

AP11 - Estou gostando muito das reflexões que estamos fazendo a respeito do ensino de Ciências.

AP13 - É, colegas, realmente é necessário refletirmos muito sobre o ensino de ciências.

AP14 - As questões trazidas pelo colega A. também são muito pertinentes e espero poder escrever um pouco mais sobre o que foi trazido.

AP22 - É, como está sendo comentado pelos colegas, recebemos algo pronto e apenas repassamos. 
As manifestações evidenciam os diálogos ocorridos em função das análises dos desenhos, da escuta da poesia e das leituras dos textos. Os alunos-professores tornam evidentes, uns para com os outros, suas necessidades de reorientar as práticas (AP7demonstram a preocupação e consciência de que é preciso mudar). Expõem-se não escondendo suas incertezas e dificuldades, mas se percebem como fazendo parte de um coletivo que pode buscar opções novas para realizarem sua profissão; sentem-se participantes de uma comunidade de prática, no sentido em que Lave e Wenger (2002) definem, uma vez que partilham uma preocupação, identificam uma série de problemas e se orientam coletivamente para a busca de solução deles (APl - Temos muitas coisas a discutir).

Assim sendo, os significados são construídos e negociados coletivamente em sistemas de relações amplos nos quais atividades, tarefas, funções e noções não existem em isolamento (LAVE; WENGER, 2002). No caso dos alunos-professores, sujeitos da pesquisa, este conjunto de manifestações expressa possibilidades de significados que vão sendo gestados por cada sujeito compondo sua identidade. Cada um estabelece suas próprias relações conceituais, e o mapa dessas relações é o que ajuda a compor a identidade de cada sujeito. No entanto, estas redes conceituais somente podem ser estabelecidas a partir da pertença a comunidades sociais. Para Lave e Wenger (2002) a participação num grupo social "[...] sugere um foco muito explícito na pessoa, mas como pessoa-no-mundo como membros de uma comunidade sociocultural" (p. 169).

As escritas de cada participante entrelaçam-se e motivam reflexões e pensamentos sobre si mesmo e sobre seu pertencimento ao coletivo. As formas de referência a cada situação somente têm significados porque esses alunos-professores compõem uma comunidade de prática, ou seja, partilham experiências procurando repostas e interpretações coletivamente. As relações são o que define cada pessoa e ao mesmo tempo é a pessoa que as define. A identidade é construída na comunidade, mas a aprendizagem é construção de identidade, logo, a aprendizagem somente ocorre na relação comunitária (LAVE; WENGER, 2002). Nessas comunidades “[...] a aprendizagem envolve a pessoa inteira; implica não somente uma relação com atividades específicas, mas uma relação com comunidades sociais, implica tornar-se um participante pleno" (LAVE; WENGER, 2002, p. 169). E esse participante contribui com sua atitude investigativa, pois pesquisa sobre suas compreensões e interpretações, sobre sua realidade em interação com cada participante do grupo. 
Por isso, pesquisar é conhecer-se, descobrir-se pertencendo ao seu mundo, é perceber as transformações em si mesmo e, consequentemente, do espaço social no qual vive. Nestas perspectivas, a investigação é definida como principio educativo e formativo (DEMO, 2002). A pesquisa não pode aparecer como mera estratégia pedagógica senão como postura de trabalho, como pressuposta ao aprendizado.

A partir dessas análises, constatou-se que o fórum de discussões pode tornar-se um ambiente de formação e aprendizagem colaborativo uma vez que contribui para a atitude investigadora, para a participação em conjunto na busca de soluções para a coletividade. As manifestações dos alunos-professores revelam sua familiaridade com o grupo ao qual pertencem, sentem-se colaboradores do debate e capazes de aprender e contribuir para avanços teórico-práticos.

\section{Considerações finais}

Os relatos e análises aqui apresentados procuraram trazer contribuições para o campo da formação docente, em especial para o ensino de ciências nos anos iniciais. A pesquisa realizada esteve ancorada em dados empíricos limitados a um período do curso de Licenciatura em Pedagogia, conforme comentado anteriormente. No entanto, foi possível constatar o quanto podem ser significativas e desafiadoras as atividades que se propõem a romper com certas práticas obsoletas e repetitivas em relação à formação de professores. Ficam evidentes as dificuldades percebidas pelos alunos-professores em relação a sua formação, o que acarreta procedimentos pedagógicos que não motivam seus alunos. Mas, em contrapartida, os alunos-professores manifestam pensamentos e atitudes de inconformidade com suas aulas, revelando a vontade de construir novos conceitos e novas mentalidades.

Quando se procurou integrar as categorias acima analisadas constatou-se que se interligam e interagem formando uma totalidade, trazendo indicadores significativos a respeito das possibilidades de ressignificação das práticas pedagógicas. Relembram-se aqui essas categorias para tornar mais explícita essa proposição uma vez que revelaram, em sua sequência, para a atividade formativa dos alunos-professores, um caminho metodológico não previsto no início da pesquisa: a) tomada de consciência sobre a própria prática; b) novas práticas de aprendizado sobre a natureza e o ensino de ciências; c) a arte no ensino de ciências; d) formação a partir de práticas colaborativas.

Concluiu-se que: as práticas colaborativas incentivam a tomada de consciência sobre a realidade; os processos de problematização e ressignificação ocorrem por ações 
de interação criativas das quais emerge a novidade; as ciências e as artes, por se entrelaçarem histórica e culturalmente, oferecem possibilidades de superação de modelos curriculares segmentados, abrindo caminhos para um contexto interdisciplinar de construção do conhecimento.

Por essas considerações evidenciamos a necessidade de se ampliarem as pesquisas na formação continuada a fim de que esta possa receber cada vez mais atenção nas instituições de ensino, motivando a proposição de outras formas de realizar a educação. É nos espaços institucionais que os professores se encontram, seja presencialmente ou a distância; é nesses espaços que se deverão ampliar as possibilidades de investigações, debates, discussões e planejamentos para construções coletivas visando a elaboração de novos significados para a educação.

A formação plena dos alunos só poderá ser perseguida à medida que os professores tenham a possibilidade de realizar em si mesmos essa plenitude. Os espaços colaborativos deverão ser comunidades de prática nas quais a construção da identidade de cada um se processe pelo sentimento de pertencimento ao grupo contribuindo no planejamento e na realização de projetos que digam respeito aos anseios comuns. Este é um aspecto que necessita ser enfatizado: a aprendizagem envolve a construção de identidade. O professor, enquanto se constitui como sujeito autor de sua profissão, criativo e inventivo, posiciona-se como referencial para seus alunos. Estes receberão motivação para realizarem esse ideal de descoberta do mundo e de si mesmos em interação permanente com a realidade. Assim, professor e aluno aprendem um com o outro.

A experiência aqui relatada dá indicadores das inúmeras possibilidades que se abrem quando se procura romper com as inércias e ideologias institucionais que se arrastam por décadas na educação. A proposta de formar o professor com competências para a pesquisa visa à superação da função docente como técnico que repete informações, trazendo uma nova perspectiva em que ele é produtor de conhecimentos, adquirindo autonomia profissional. A sua autoestima está relacionada com esse sentimento de ser capaz de elaborar seus próprios significados a partir de movimentos colaborativos de entendimento da realidade.

Cabe salientar que a atitude investigativa significa não ficar preso a técnicas e modelos de pesquisa, mas tornar a própria pesquisa também um objeto a ser analisado e questionado. Parte-se de pressupostos e planejamentos, de rigor e dedicação, mas mantém-se abertura e escuta atenta para correções de rumo e alterações de metas. Assim 
a proposta de investigação como fundamento de aprendizagem cumpre seu papel enquanto impede que se construam conhecimentos definitivos e cristalizados. A pesquisa é dinâmica e transformadora também de si mesma. Essa é uma das vias pela qual o ensino de ciências pode contribuir para a formação plena das pessoas.

\section{Referências}

ALMEIDA, M. L. P. Políticas de educação e Estado Avaliador na América Latina: uma análise para além das avaliações externas. Revista Iberoamericana sobre Calidad, Eficacia y Cambio en Educación, v.11, n.4, p. 77-91. 2013.

AMARAL, M. B. Telenatureza e a construção do natural: um olhar sobre imagens de natureza na publicidade. In: OLIVEIRA, D. L. (Org.). Ciências nas salas de aula. Porto Alegre: Ed. Mediação, 1997. p. 83-96.

AZEVEDO, M. N.; ABIB, M. L. V. S. Pesquisa-Ação e a Elaboração de Saberes Docentes em Ciências. Investigações em Ensino de Ciências, v. 18, n.1, p. 55-75, 2013.

BARROS, J. C.; SOUZA, P. N. Práticas discursivas de uma tutora em fóruns de discussão online. Veredas On Line - Atemática - 1/2011, p. 383-397 - PPG Linguística/UFJF - Juiz de Fora. 2011.

BASTOS, F. P.; ALBERTI, T. F.; MAZZARDO, M. D. Ambientes virtuais de ensinoaprendizagem: os desafios dos novos espaços de ensinar e aprender e suas implicações no Contexto escolar. Cinted-UFRGS, v. 3, n. 1, maio, 2005. Disponível em:

http://seer.ufrgs.br/renote/article/viewFile/13740/7969 Acesso em 02 de agosto de 2014.

BELLONI, M. L. Ensaio sobre a Educação a distância no Brasil. Educação \& Sociedade, ano XXIII, n. 78, /2002.

BRASIL. Ministério da Educação. Secretaria de Educação Básica. Secretaria de Educação Continuada, Alfabetização, Diversidade e Inclusão. Diretrizes Curriculares Nacionais Gerais da Educação Básica / Ministério da Educação. Secretaria de Educação Básica. Diretoria de Currículos e Educação Integral. Brasília: MEC, SEB, DICEI, 2013.

BRAUN, J. C. 50 anos de poesia: antologia poética. Martins Livreiro: Porto AlegreRS, 1996.

CHASSOT, A. Alfabetização científica: uma possibilidade para a inclusão social. Revista Brasileira de Educação. n 21, , p. 157-158, 2002.

DEMO, P. Educar pela Pesquisa. 5a ed. Campinas: Autores Associados, 2002.

FREIRE, M. A paixão de conhecer o mundo: relato de uma professora. Rio de Janeiro: Paz e Terra, 1983.

FREIRE, P. Pedagogia do oprimido. $9^{a}$ ed. Rio de Janeiro: Paz e Terra, 1981. 
GATTI, B. Formação de Professores no Brasil: Características e Problemas. Educação e Sociedade, v. 31, n. 113, p. 1355-1379, 2010.

HERNÁNDEZ, F. Transgressão e mudança na educação: os projetos de trabalho. Porto Alegre: ArtMed, 1998.

IMBERNÓN, F. Formação Docente e profissional: formar-se para a mudança e a incerteza. 9 ed. São Paulo: Cortez, 2011.

LAVE, J.; WENGER, E. Prática, pessoa, mundo social. In: DANIELS, H. Uma introdução a Vigotski. São Paulo: Edições Loyola, 2002.

LEVY, P. O que é virtual?. São Paulo: Ed. 34, 1996.

MANFREDO, E. C. G. Metodologia de Projetos e Formação de Professores: uma Experiência Significativa na Prática de Ensino e Ciências Naturais. Experiências em Ensino de Ciências, v.1, n.3, p. 45-57, 2006.

MORAES, R.; GALIAZZI, M. C. Análise Textual Discursiva. 2 ed. Ijuí: Ed. Unijuí. 2011.

NÓVOA, A. Devolver a formação de professores aos professores. Cadernos de Pesquisa em Educação, v. 18, n. 35, p. 11-22, 2012.

OSTROWER, F. Criatividade e processos de criação. $6^{\text {a }}$ ed. Petrópolis: Vozes, 1987.

OVIGLI, D. F.B.; BERTUCCI, M. C. A formação para o ensino de ciências naturais nos currículos de pedagogia das instituições públicas de ensino superior paulistas. Ciências \& Cognição, v.14, n.2, p. 194-209, 2009.

PONTE, J. P. Pesquisar para compreender e transformar a nossa própria prática. Educar em Revista, Curitiba, v.24, 37-66, 2004.

RAMOS, L. B. da C.; ROSA, P. R. da S. O ensino de ciências: fatores intrínsecos e extrínsecos que limitam a realização de atividades experimentais pelo professor dos anos iniciais do ensino fundamental. Investigações em Ensino de Ciências, v.13, n.3, p.299-331, 2008.

ROSA, R. T. D.; OLIVEIRA, D. L. Repensando o ensino de Ciências a partir de novas histórias de Ciências. Ciências nas Salas de Aula. $3^{\text {a }}$ ed. Porto Alegre: Mediação, 1999.

SASSERON, L. H., Alfabetização Científica no Ensino Fundamental: Estrutura e Indicadores deste processo em sala de aula. 2008, 265p. Tese (Doutorado) - Faculdade de Educação, Universidade de São Paulo, São Paulo, 2008.

SCHÄFER, E. D. A.; OSTERMAN, F. Autonomia profissional na formação de professores: uma análise de entrevistas realizadas num mestrado profissional em ensino de física. Revista Electrónica de Enseñanza de las Ciencias, v.12, n.2, p. 287-312, 2013. 
URZETTA, F. C.; CUNHA, A. M. de O. Análise de uma proposta colaborativa de formação continuada de professores de ciências na perspectiva do desenvolvimento profissional docente. Ciência \& Educação, Bauru, v. 19, n. 4, p. 841-858, 2013.

ZANETIC, J. Física e literatura: construindo uma ponte entre as duas culturas. História, Ciências, Saúde - Manguinhos, v. 13 (suplemento), p. 55-70, 2006.

ZOMPERO, A. F.; FIGUEIREDO, H. Aplicação de Atividades Investigativas na Disciplina de Ciências: Estudo de Caso Para a Formação Docente. In: IX CONGRESO INTERNACIONAL SOBRE INVESTIGACIÓN EN DIDÁCTICA DE LAS CIENCIAS. Girona. Anais... Girona, 2013.

JOSÉ FRANCISCO FLORES. Doutorando do Programa de Pós-Graduação em Educação em Ensino de Ciências da Pontifícia Universidade Católica do Rio Grande do sul (PUCRS). Mestre pela Universidade Federal do Rio Grande do Sul (2001). Professor de Física do Colégio Anchieta de Porto Alegre/RS.

JOÃO BERNARDES DA ROCHA FILHO. Pós-doutor em Enseñanza de las Ciencias (Facultad de Educación/PUC Chile). Doutor em Engenharia na área de metrologia e instrumentação (LABMETRO/UFSC). Mestre em Educação (FACED/PUCRS). Especialista em Metodologia do Ensino Superior (FACED/PUCRS). Especialista em psicossomática (FACIS/SP). Licenciado em Física (FAFIS/PUCRS). Bacharel em Filosofia UNISUL/SC). Técnico em Eletrônica (IM/SP). Professor titular da Faculdade de Física da Pontifícia Universidade Católica do Rio Grande do Sul. Professor permanente do Programa de Pós-Graduação em Educação em Ensino de Ciências (PPGEDUCEM-PUCRS)

LUCIUS RAFAEL SICHONANY SAMUEL. Doutorando do Programa de PósGraduação em Educação em Ensino de Ciências (PPGEDUCEM-PUCRS). Mestre pelo PPGEDUCEM-PUCRS. Professor de Física da PUCRS. Professor de Física do Colégio Anchieta de Porto Alegre/RS.

Recebido: 13 de outubro de 2014

Revisado: 25 de março de 2015

Aceito: 23 de abril de 2015 